ISSN: 1410-8917

Jurnal Kimia

Sains \&

Aplikasi
Jurnal Kimia Sains dan Aplikasi Journal of Scientific and Applied Chemistry

Journal homepage: http://ejournal.undip.ac.id/index.php/ksa

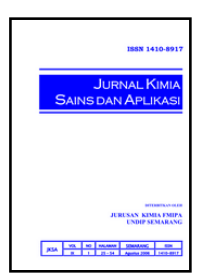

\title{
Pengaruh Variasi Jenis Asam terhadap Karakter Nanosilika yang Disintesis dari Abu Sekam Padi
}

\author{
Dini Hayati ${ }^{a}$, Pardoyo ${ }^{\mathrm{a},{ }^{*}}$, Choiril Azmiyawati ${ }^{\mathrm{a}}$ \\ a Inorganic Laboratory, Chemistry Department, Faculty of Sciences and Matematics, Diponegoro University, Jalan Prof. Soedarto, \\ Tembalang, Semarang 50275, Telepon (024) 7474754 \\ * Corresponding author: pardoyoku@live.undip.ac.id
}

\begin{tabular}{|c|c|}
\hline Article Info & Abstract \\
\hline $\begin{array}{l}\text { Keywords: } \\
\text { husk rice ash, sol- } \\
\text { gel, nanosilica }\end{array}$ & $\begin{array}{l}\text { Rice husk ash contains } 80 \% \text { silica therefore it can be utilized as raw material in synthesis } \\
\text { of nanosilica. In this research, the synthesis of nanosilika from rice husk ash with } \\
\text { variation of acid type which were } \mathrm{HCl}, \mathrm{H}_{2} \mathrm{SO}_{4} \text {, and } \mathrm{H}_{3} \mathrm{PO}_{4} \text { with each concentration } 3 \mathrm{M} \text { has } \\
\text { been conducted. Nanosilicas were achieved by reacting sodium silicate which was } \\
\text { obtained by dissolving rice husk ash in } 2.5 \mathrm{M} \mathrm{NaOH} \text { solution with acid catalyst to pH } 7 \\
\text { via sol gel process. Based on the results, it was obtained that nanosilica produced by } \\
\text { posphat acid catalyst had a surface morphology size of } 40 \text { to } 60 \mathrm{~nm} \text {. Nanosilica produced } \\
\text { by sulfuric acid catalyst }\left(\mathrm{H}_{2} \mathrm{SO}_{4}\right) \text { had the largest total surface area of } 158.168 \mathrm{~m}^{2} \text { and pore } \\
\text { volume among the three acid variations compared to hydrochloric acid (HCl) and } \\
\text { phosphate }\left(\mathrm{H}_{3} \mathrm{PO}_{4}\right) \text { catalysts. }\end{array}$ \\
\hline
\end{tabular}

\section{Abstrak}

Kata kunci:

Abu sekam padi, sol-gel, nanosilika
Abu sekam padi mengandung $80 \%$ silika sehingga dapat dimanfaatkan sebagai bahan baku dalam sintesis nanosilika. Pada penelitian ini dilakukan sintesis nanosilika dari abu sekam padi dengan variasi jenis asam yaitu $\mathrm{HCl}, \mathrm{H}_{2} \mathrm{SO}_{4}$, dan $\mathrm{H}_{3} \mathrm{PO}_{4}$ dengan konsentrasi masing-masing 3M. Nanosilika diperoleh dengan mereaksikan natrium silikat yang diperoleh dengan melarutkan abu sekam padi dalam larutan $\mathrm{NaOH}$ 2,5 M kemudian proses sol gel dengan katalis asam hingga $\mathrm{pH}$ 7. Berdasarkan hasil penelitian diperoleh nanosilika dengan katalis asam posfat dan diperoleh ukuran morfologi permukaan 40 sampai $60 \mathrm{~nm}$. Nanosilika yang dihasilkan dengan katalis asam sulfat $\left(\mathrm{H}_{2} \mathrm{SO}_{4}\right)$ menghasilkan luas permukaan dan volume total pori paling besar diantara ketiga variasi asam yang digunakan katalis asam klorida $(\mathrm{HCl})$ dan asam posfat $\left(\mathrm{H}_{3} \mathrm{PO}_{4}\right)$, yaitu luas permukaan $158,168 \mathrm{~m} 2 / \mathrm{g}$, volume total pori $0,2378 \mathrm{cc} / \mathrm{g}$, dan diameter pori rata-rata $6 \mathrm{~nm}$.

\section{Pendahuluan}

Sekam padi terdiri dari $40 \%$ selulosa, $30 \%$ lignin, dan $20 \%$ silika [1] sedangkan pada abu sekam padi mengandung $80 \%$ silika sehingga dapat dimanfaatkan sebagai bahan baku dalam sintesis nanosilika.

Dengan perkembangan teknologi, aplikasi penggunaan silika pada industri semakin meningkat. Terutama penggunaan silika dalam ukuran kecil sampai skala nano partikel, banyak dimanfaatkan sebagai material building, yaitu sebagai bahan campuran pada beton. Rongga yang kosong di antara partikel semen akan diisi oleh nanosilika sehingga berfungsi sebagai bahan penguat beton dan meningkatkan daya tahannya.

Beberapa peneliti menggunakan asam yang berbeda dalam sintesis nanosilika. Noushad, dkk. [2] menggunakan asam organik untuk presipitasi larutan natrium silikat, sementara Liou dan Yang [3] menggunakan asam klorida, asam sulfat, asam sitrat, dan asam oksalat. Penggunaan asam yang berbeda 
dalam sintesis nanosilika mempengaruhi luas permukaan dan porositas nanosilika.

Pada penelitian ini, akan dilakukan sintesis nanosilika dari abu sekam padi dengan variasi asam yaitu asam klorida, asam sulfat, dan asam posfat masing-masing konsentrasi $3 \mathrm{M}$ dengan metode sol-gel pada kondisi $\mathrm{pH} 7$.

\section{Metode Penelitian}

\section{Alat dan Bahan}

Bahan kimia yang digunakan dalam penelitian ini meliputi air destilasi, asam klorida $(\mathrm{HCl}) 37 \%$, asam sulfat $\left(\mathrm{H}_{2} \mathrm{SO}_{4}\right) 96 \%$, asam posfat $\left(\mathrm{H}_{3} \mathrm{PO}_{4}\right) 85 \%$, natrium hidroksida $(\mathrm{NaOH})$, dan etanol pro analis. Alat-alat yang digunakan meliputi peralatan gelas, magnetic stirrer, oven, furnace, neraca digital. Nanosilika hasil sintesis dikarakterisasi dengan instrument fourier transform infrared spectrometer (FTIR), gas sorption analyzer (GSA), dan scanning electron microscope-energy dispersive X-ray (SEM-EDX).

\section{Ekstraksi silika}

Sekam padi direndam dalam air destilasi selama satu malam dan dicuci dengan air destilasi untuk menghilangkan debu dan tanah. Sekam padi dikeringkan dalam oven pada suhu $110^{\circ} \mathrm{C}$ selama 2 jam. Sekam padi hasil pengeringan dipanaskan dalam larutan $\mathrm{HCl} 1 \mathrm{M}$ (dalam wadah air) pada suhu $75^{\circ} \mathrm{C}$ selama 1 jam untuk menghilangkan pengotor ion logam. Suspensi disaring dan residu padatannya dicuci dengan air destilasi hingga netral. Selanjutnya dilakukan pengarangan sekam padi. Arang sekam padi difurnace pada suhu $700^{\circ} \mathrm{C}$ selama 4 jam dengan laju kenaikan suhu $5^{\circ} /$ menit untuk memperoleh abu sekam padi. Sepuluh gram abu sekam padi dilarutkan dalam $200 \mathrm{~mL}$ larutan natrium hidroksida $(\mathrm{NaOH}) \quad 2,5 \quad M \quad$ dan dipanaskan dalam wadah teflon selama 2 jam pada suhu $100^{\circ} \mathrm{C}$ dan dihasilkan larutan natrium silikat.

\section{Sintesis Nanosilika dengan Variasi Asam}

Nanosilika dihasilkan dengan metode sol gel menggunakan variasi asam $\left(\mathrm{HCl}, \mathrm{H}_{2} \mathrm{SO}_{4}\right.$, dan $\mathrm{H}_{3} \mathrm{PO}_{4}$ ) dengan konsentrasi sama yaitu $3 \mathrm{M}$. Larutan natrium silikat dimasukkan dalam gelas beaker dan diaduk dengan magnetic stirrer. Larutan natrium silikat ditambahkan etanol pro analis dengan perbandingan 1:0,25 dan didiamkan selama 10 menit dengan pengadukan konstan, selanjutnya ke dalam larutan natrium silikat+etanol, larutan asam $3 \mathrm{M}$ ditambahkan tetes demi tetes hingga $\mathrm{pH} 7$ yang diamati dengan kertas pH universal dan diaduk dengan magnetic stirrer hingga terbentuk gel. Gel yang terbentuk didiamkan selama 2 hari, selanjutnya dioven pada suhu $80^{\circ} \mathrm{C}$ hingga terbentuk xerogel. Xerogel yang terbentuk dicuci dengan air deionisasi mendidih hingga netral untuk menghilangkan garam natrium yang terbentuk selama proses sol gel. Serbuk silika yang diperoleh digerus dengan mortal dan dikeringkan pada suhu $80^{\circ} \mathrm{C}$ hingga kering. Selanjutnya, difurnace pada suhu $550^{\circ} \mathrm{C}$ untuk menghilangkan senyawa organik.

\section{Hasil dan Pembahasan}

\section{Sintesis nanosilika}

Nanosilika disintesis dengan metode sol-gel menggunakan precursor $\mathrm{SiO}_{2}$ yang diektraksi dari abu sekam padi dengan melarutkan abu sekam padi ke dalam larutan $\mathrm{NaOH}$ 2,5 M menghasilkan larutan natrium silikat berwarna bening.

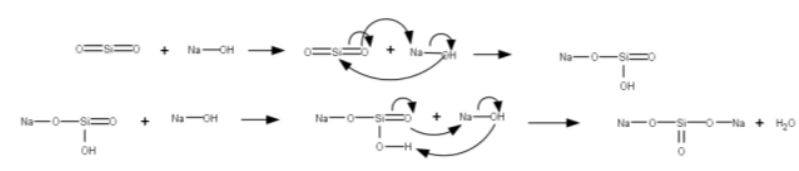

Gambar 1. Mekanisme reaksi pembentukan natrium silikat [4].

Metode sol-gel meliputi tahapan proses hidrolisis dan kondensasi sebagai berikut.

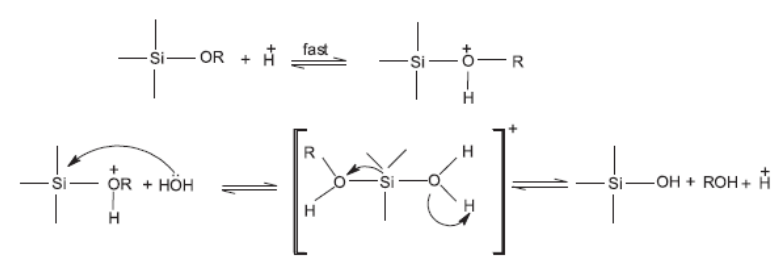

Gambar 2. Mekanisme reaksi hidrolisis [4]

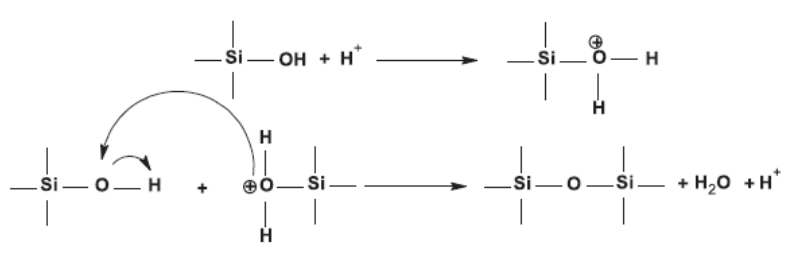

Gambar 3. Mekanisme reaksi kondensasi [4]

Penambahan asam dilakukan tetes demi tetes hal ini bertujuan untuk mengatur kondisi keasaman pada $\mathrm{pH}$ 7. Pada $\mathrm{pH} 7$ jumlah gugus silanol $(\mathrm{Si}-\mathrm{OH})$ dan gugus siloksi $\left(\mathrm{Si}-\mathrm{O}^{-}\right)$berada dalam jumlah yang sama sehingga reaksi pembentukan gel berlangsung cepat dan stabil.
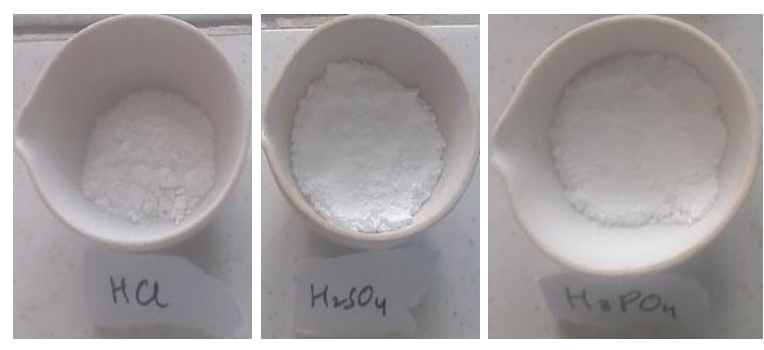

Gambar 4. Nanosilika hasil sintesis

Tabel 1. Pengaruh variasi asam terhadap massa nanosilika hasil sintesis

\begin{tabular}{cccc}
\hline $\begin{array}{c}\text { Jenis } \\
\text { Asam }\end{array}$ & $\begin{array}{c}\text { Konsen- } \\
\text { trasi (M) }\end{array}$ & pH & $\begin{array}{c}\text { Hasil setelah } \\
\text { furnace }(\mathrm{gr})\end{array}$ \\
\hline $\mathrm{HCl}$ & 3 & 7 & 0,7413 \\
$\mathrm{H}_{2} \mathrm{SO}_{4}$ & 3 & 7 & 1,0377 \\
$\mathrm{H}_{3} \mathrm{PO}_{4}$ & 3 & 7 & 0,9412 \\
\hline
\end{tabular}


Berdasarkan hasil tabel 1 terlihat bahwa $\mathrm{H}_{2} \mathrm{SO}_{4}$ menghasilkan serbuk silika dengan massa paling besar. Hal ini dapat dijelaskan berdasarkan perbedaan jumlah $\mathrm{H}^{+}$nya. Asam berperan sebagai katalis dan reaktan dalam pembentukan silika gel. Asam klorida merupakan asam monoprotik yang mampu melepaskan $1 \mathrm{H}^{+}$ sehingga untuk mencapai kondisi $\mathrm{pH} 7$ jumlah ( $\mathrm{Si}-$ $\mathrm{OH}=\mathrm{Si}-\mathrm{O}^{-}$) membutuhkan jumlah yang lebih banyak dibandingkan $\mathrm{H}_{2} \mathrm{SO}_{4}$ dan $\mathrm{H}_{3} \mathrm{PO}_{4}$. Asam sulfat merupakan asam diprotik yang mampu melepaskan $2 \mathrm{H}^{+}$dan membutuhkan jumlah yang lebih banyak dibandingkan $\mathrm{H}_{3} \mathrm{PO}_{4}$ untuk mencapai kondisi pH 7, dengan penambahan dalam jumlah yang lebih banyak juga dihasilkan anion dari asamnya dalam jumlah yang lebih banyak sehingga dihasilkan jumlah nanosilika paling banyak. Asam posfat $\left(\mathrm{H}_{3} \mathrm{PO}_{4}\right)$ merupakan asam poliprotik yang mampu melepaskan $3 \mathrm{H}^{+}$sehingga membutuhkan jumlah yang paling sedikit untuk mencapai $\mathrm{pH} 7$.

\section{Karakterisasi nanosilika}

Nanosilika hasil sintesis dari abu sekam padi dikarakterisasi dengan spektrofotometer IR untuk mengetahui gugus silanol ( $\mathrm{Si}-\mathrm{OH})$ dan siloksan ( $\mathrm{Si}-\mathrm{O}-$ $\mathrm{Si}$ ), scanning electron microscope (SEM) untuk mengetahui ukuran morfologi permukaan, dan gas sorption analyzer (GSA) untuk mengetahui luas permukaan serta porositas nanosilika hasil sintesis.

Gambar 5 menunjukkan spektra IR silika yang disintesis dari abu sekam padi dengan variasi jenis asam sebagai reaktan dan katalis. Dilihat dari spektra IR menunjukkan bahwa nanosilika hasil sintesis dengan asam klorida dan asam posfat didominasi oleh gugus siloksan (Si-O-Si), hal ini ditunjukkan tidak adanya serapan pada bilangan gelombang 900-an yang menunjukkan vibrasi ikatan gugus silanol ( $\mathrm{Si}-\mathrm{OH}$ ). Sementara nanosilika yang disintesis dengan katalis asam sulfat menunjukkan adanya serapan pada bilangan gelombang 900-an.

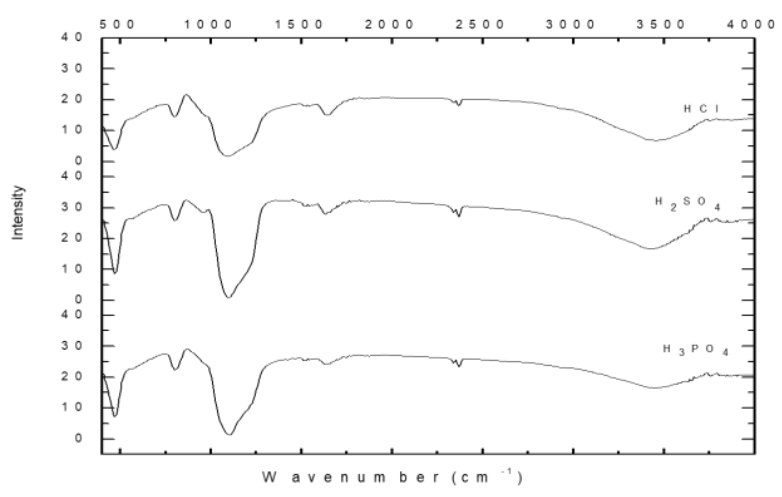

Gambar 5. Spektra IR nanosilika
Tabel 2. Interpretasi spektra IR

\begin{tabular}{|c|c|c|c|}
\hline \multicolumn{3}{|c|}{ Bilangan gelombang $\left(\mathrm{cm}^{-1}\right)$} & \multirow{2}{*}{ Gugus fungsi } \\
\hline $\mathrm{HCl}$ & $\mathrm{H}_{2} \mathrm{SO}_{4}$ & $\mathrm{H}_{3} \mathrm{PO}_{4}$ & \\
\hline 470,63 & 470,63 & 470,63 & Vibrasi tekuk $\equiv \mathrm{Si}-\mathrm{O}-\mathrm{Si} \equiv$ \\
\hline \multirow[t]{2}{*}{802,39} & 802,39 & 802,39 & Vibrasi ulur simetri $\equiv \mathrm{Si}-\mathrm{O}-\mathrm{Si} \equiv$ \\
\hline & 956,69 & & Vibrasi ulur Si-O dari Si-OH \\
\hline 1095,57 & 1103,28 & 1103,28 & Vibrasi ulur asimetri $\equiv \mathrm{Si}-\mathrm{O}-\mathrm{Si} \equiv$ \\
\hline 1635,64 & 1635,64 & 1635,64 & Vibrasi tekuk O- $\mathrm{H}$ dari $\mathrm{H}_{2} \mathrm{O}$ \\
\hline 3448,72 & 3452,58 & 3448,72 & $\begin{array}{c}\text { Vibrasi ulur } \mathrm{O}-\mathrm{H} \text { dari } \equiv \mathrm{Si}-\mathrm{OH} \text { atau } \\
\qquad \mathrm{H}_{2} \mathrm{O}\end{array}$ \\
\hline
\end{tabular}

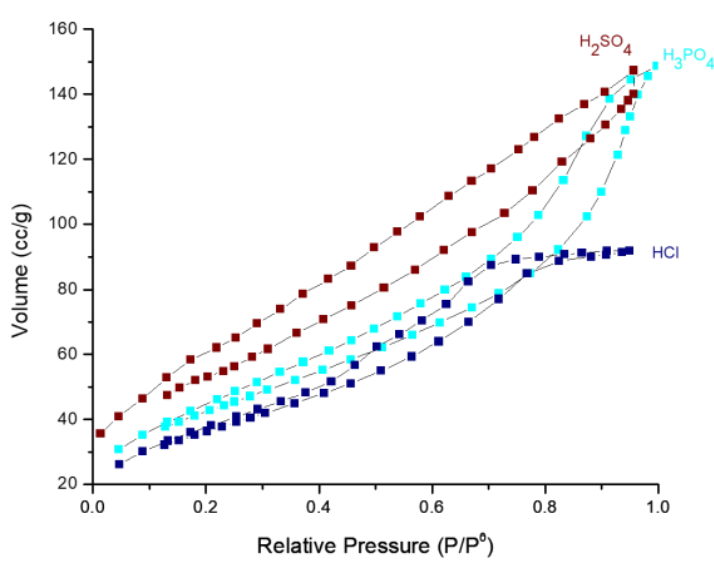

Gambar 6. Kurva isothermal adsorpsi-desorpsi nanosilika hasil sintesis dengan variasi asam

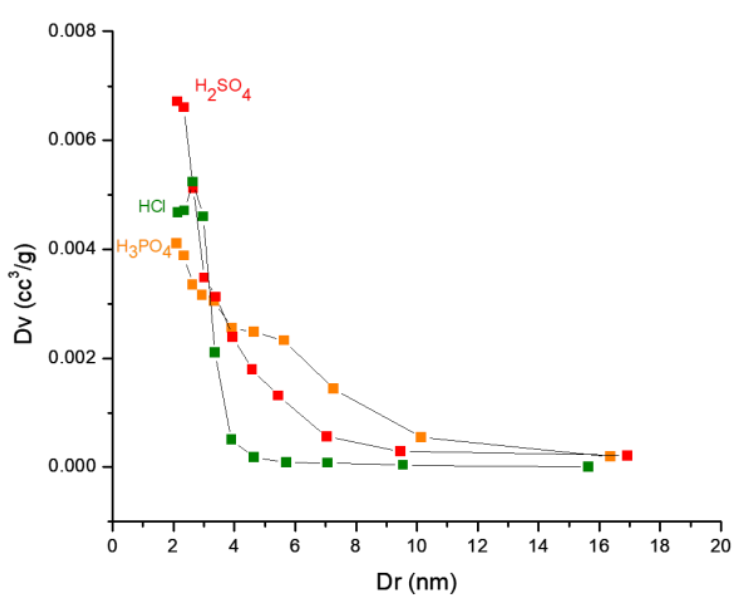

Gambar 7. Kurva distribusi ukuran pori nanosilika hasil sintesis dengan variasi asam

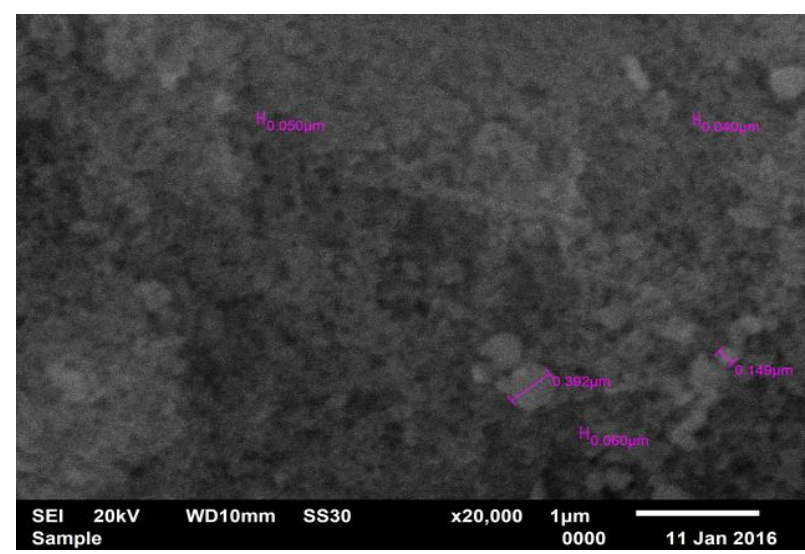

Gambar 8. Citra SEM nanosilika 


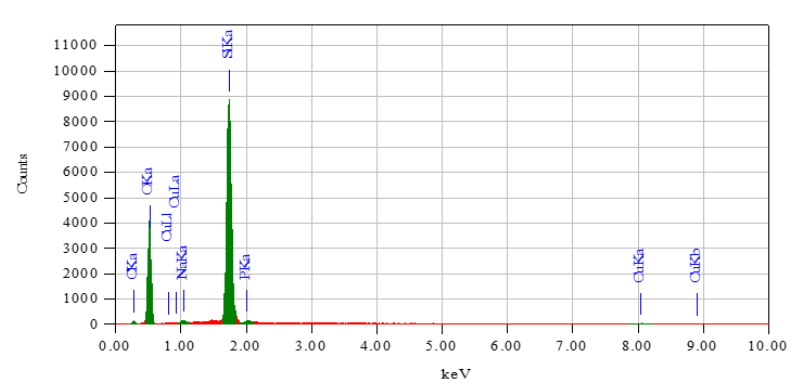

Gambar 9. EDX nanosilika

Gambar 6 menunjukkan hasil analisis GSA adsorpsi gas nitrogen dari nanosilika hasil sintesis yang digambarkan dengan kurva adsorpsi-desorpsi isotermal. Kurva adsorpsi-desorpsi isotermal nanosilika hasil sintesis dengan variasi asam merupakan kurva isotermal tipe IV (berdasarkan IUPAC) dengan loop histerisis type H2. Loop histerisis disebabkan oleh kondensasi kapiler dan mengindikasikan bahwa nanosilika hasil sintesis tergolong mesopori dengan diameter pori $>2 \mathrm{~nm}-50 \mathrm{~nm}$. Gambar 7 menunjukkan kurva diferensial distribusi ukuran pori yaitu hubungan bagaimana perubahan ukuran pori terhadap volume pori karena jumlah pori yang banyak. Dapat terlihat bahwa dengan penggunaan asam klorida $(\mathrm{HCl})$ sebagai reaktan dan katalis dalam proses sol-gel menghasilkan nanosilika dengan distribusi pori yang lebih seragam (uniform) dibandingkan asam sulfat dan asam posfat. Hal ini ditunjukkan oleh adanya peak pada kurva diferensial distribusi ukuran pori ( $D v / D r)$. Kurva asam sulfat $\left(\mathrm{H}_{2} \mathrm{SO}_{4}\right)$ menunjukkan distribusi ukuran pori yang lebih seragam dibandingkan asam posfat $\left(\mathrm{H}_{3} \mathrm{PO}_{4}\right)$ yang menunjukkan distribusi ukuran pori kurang seragam tapi tersebar di beberapa ukuran.

Tabel 3. Luas permukaan, volume total pori, dan ukuran pori nanosilika hasil sintesis dengan variasi asam

\begin{tabular}{cccc}
\hline $\begin{array}{c}\text { Jenis } \\
\text { asam }\end{array}$ & $\begin{array}{c}\text { Luas } \\
\text { permukaan } \\
(\mathrm{m} 2 / \mathrm{g})\end{array}$ & $\begin{array}{c}\text { Volume } \\
\text { total pori } \\
(\mathrm{cc} / \mathrm{g})\end{array}$ & $\begin{array}{c}\text { Diameter } \\
\text { pori rata- } \\
\text { rata }(\mathrm{nm})\end{array}$ \\
\hline $\mathrm{HCl}$ & 130,867 & 0,1420 & 4,34 \\
$\mathrm{H} 2 \mathrm{SO} 4$ & 158,168 & 0,2378 & 6 \\
$\mathrm{H} 3 \mathrm{PO} 4$ & 112,5 & 0,2274 & 8 \\
\hline
\end{tabular}

Berdasarkan data pada Tabel 4 terlihat bahwa dengan penggunaan asam sulfat $\left(\mathrm{H}_{2} \mathrm{SO}_{4}\right)$ sebagai reaktan dan katalis dalam proses sol-gel menghasilkan nanosilika dengan luas permukaan paling besar meskipun distribusi ukuran pori dengan penggunaan asam klorida lebih seragam, namun intensitas peaknya (gambar 7) lebih tinggi. Sedangkan dengan penggunaan katalis $\mathrm{H}_{3} \mathrm{PO}_{4}$ menghasilkan luas permukaan paling kecil karena distribusi ukuran porinya tidak seragam dan intensitas peaknya rendah.

Berdasarkan intensitas peak Dv/Dr pada kurva diferensial distribusi ukuran pori menunjukkan volume total pori dan ukuran pori rata-rata pada kurva $\mathrm{HCl}$ paling kecil dibandingkan $\mathrm{H}_{2} \mathrm{SO}_{4}$ dan $\mathrm{H}_{3} \mathrm{PO}_{4}$. Hal ini karena distribusi ukuran pori dengan penggunaan asam klorida ( $\mathrm{HCl}$ ) paling seragam pada ukuran pori kecil yaitu 2-4 nm. Penggunaan katalis $\mathrm{H}_{2} \mathrm{SO}_{4}$ menghasilkan nanosilika dengan volume total pori paling besar karena luas permukaannya paling besar dengan distribusi ukuran pori yang relative seragam pada ukuran pori 2$7 \mathrm{~nm}$. Sedangkan penggunaan $\mathrm{H}_{3} \mathrm{PO}_{4}$ menghasilkan nanosilika dengan ukuran pori rata-rata paling besar karena distribusi ukuran porinya tidak seragam tapi tersebar di beberapa ukuran.

Dari citra SEM (Gambar 8) yang diperoleh menunjukkan bahwa nanosilika berhasil disintesis dengan menggunakan katalis asam posfat dengan ukuran morfologi permukaan yaitu 40 sampai $60 \mathrm{~nm}$.

Tabel 4. Data EDX

\begin{tabular}{cc}
\hline Unsur & \% Massa \\
\hline $\mathrm{O}$ & 57,97 \\
$\mathrm{Na}$ & 0,59 \\
$\mathrm{Si}$ & 30,06 \\
$\mathrm{P}$ & 0,40 \\
\hline
\end{tabular}

Keberadaan unsur Si dan O berasal dari gugus siloksan ( $\mathrm{Si}-\mathrm{O}-\mathrm{Si})$ dan silanol $(\mathrm{Si}-\mathrm{OH})$. Adanya unsur natrium (Na) dan posfor (P) dalam jumlah sedikit berasal dari larutan sodium silikat dan anion posfat $\left(\mathrm{PO}_{4}{ }^{3-}\right)$ dari asam yang dihasilkan selama proses gelasi dengan menggunakan asam posfat $\left(\mathrm{H}_{3} \mathrm{PO}_{4}\right)$.

\section{Kesimpulan}

Berdasarkan hasil penelitian menunjukkan bahwa nanosilika berhasil disintesis dengan menggunakan katalis asam posfat dengan ukuran morfologi permukaan 40 sampai $60 \mathrm{~nm}$. Nanosilika yang disintesis dengan penggunaan asam sulfat $\left(\mathrm{H}_{2} \mathrm{SO}_{4}\right)$ sebagai katalis dan reaktan menghasilkan luas permukaan dan volume total pori yang lebih besar dibandingkan katalis asam klorida $(\mathrm{HCl})$ dan asam posfat $\left(\mathrm{H}_{3} \mathrm{PO}_{4}\right)$, dengan ukuran luas permukaan $158,168 \mathrm{~m}^{2} / \mathrm{g}$, volume total pori 0,2378 $\mathrm{cc} / \mathrm{g}$, dan diameter pori rata-rata $6 \mathrm{~nm}$.

\section{Daftar Pustaka}

[1] K Amutha, R Ravibaskar, G Sivakumar, Extraction, synthesis and characterization of nanosilica from rice husk ash, International Journal of Nanotechnology and applications, 4 (2010) 61-66.

[2] Mohammed Noushad, Ismail Ab Rahman, Noor Sheeraz Che Zulkifli, Adam Husein, Dasmawati Mohamad, Low surface area nanosilica from an agricultural biomass for fabrication of dental nanocomposites, Ceramics International, 40 (2014) 4163-4171.

[3] Tzong-Horng Liou, Chun-Chen Yang, Synthesis and surface characteristics of nanosilica produced from alkali-extracted rice husk ash, Materials Science and Engineering: B, 176 (2011) 521-529.

[4] Lok P. Singh, Sriman K. Bhattacharyya, Rahul Kumar, Geetika Mishra, Usha Sharma, Garima Singh, Saurabh Ahalawat, Sol-Gel processing of silica nanoparticles and their applications, Advances in Colloid and Interface Science, 214 (2014) 17-37. 